Vol. 23, No. 1, pp. 16 26, 2020.

\title{
Trends of Nafion-based IPMC Application and Development
}

\author{
Donghae Ho${ }^{1}$, Sooyoung $\mathrm{Cho}^{2}$, Yoon Young Choi ${ }^{1}$, Young Jin Choi ${ }^{1}$, Jeong Ho Cho ${ }^{2 \dagger}$ \\ ${ }^{1}$ Advanced Institute of Nanotechnology, Sungkyunkwan University, Suwon 16419, Korea \\ ${ }^{2}$ Chemical and Biomolecular Engineering, Yonsei University, Seoul 03722, Korea
}

\section{Nafion 기반 IPMC 응용 및 개발 동향}

\author{
호동해1, 조수영', 최윤영', 최영진, 조정호 ${ }^{\dagger}$ \\ 1성균관대학교 성균나노과학 기술원 \\ 2연세대학교 화공생명공학과
}

(Received Febrary 25, 2020; Accepted March 17, 2020)

\begin{abstract}
Recently, polymer-metal composite (IPMC)-based ionic artificial muscle has been drawing a huge attention for its excellent soft actuator performance having outstanding soft actuator performance with efficient conversion of electrical energy to mechanical energy under low working voltage. In addition, light, flexible and soft nature of IPMC and high bending strain response enabled development of versatile sensor application in association with soft actuator. In this paper, current issues of IPMC were discussed including standardizing preparation steps, relaxation under DC bias, inhibiting solvent evaporation, and improving poor output force. Solutions for these drawbacks of IPMC have recently been suggested in recent studies. After following explanation of the IPMC working mechanism, we investigate the main factors that affect the operating performance of the IPMC. Then, we reviewed the optimized IPMC actuator fabrication conditions especially for the preparation process, additive selection for a thicker membrane, water content, solvent substitutes, encapsulation, etc. Lastly, we considered the pros and cons of IPMCs for sensor application in a theoretical and experimental point of view. The strategies discussed in this paper to overcome such deficiencies of IPMCs are highly expected to provide a scope for IPMC utilization in soft robotics application.
\end{abstract}

Keywords: IPMC, soft actuator, sensor, ionic liquid.

${ }^{\dagger}$ Corresponding Author: Jeong Ho Cho

E-mail: jhcho94@yonsei.ac.kr 


\section{1. 서론}

최근 소프트 로보틱스 분야의 개발로 인해서 액추에 이터와 센서에 대한 관심이 증가하고 있다. 소프트 로 보틱스에 사용되는 파트들은 크기가 작으면서 유연 해야 한다. 이러한 특징을 만족하는 물질로써 Ionic polymer-metal composite (IPMC) 이온 고분자-금 속 복합체 (IPMC)는 최근 20년간 소프트 로보틱스와 다 양한 산업분야에서 사용되는 센서, 액추에이터로 연구 가 진행되고 있다. ${ }^{1-5)}$ 전기활성중합체 중 하나인 IPMC 는 소프트 로보틱스에 사용하기 용이한 장점을 갖고 있 다. 장점들로는 가벼운 무게, 부드러움, 전기 에너지의 효율적인 물리적 에너지로의 변환, 낮은 활성 전압에서 (1 3V) 나타나는 큰 벤딩 스트레인, 낮은 전력 소비, 빠 른 반응, 물리적이나 기계적으로 높은 내성과 안정성, 소형화의 간단함 등이 있다. ${ }^{6)}$ 상기한 특징들로 인해서 IPMC는 소프트 로보틱스에서 소프트 액추에이터로 이 용되었고 특히 마이크로 로봇과 해저 로봇과 같은 곳에 사용되었다. ${ }^{3}{ }^{7)} \mathrm{IPMC}$ 는 또한 물리적인 에너지를 전기 적인 에너지로 바꿀 수 있는 특성을 가지고 있는데 이런 특성은 센서 분야에서 스스로 감지하는 특성으로 주목 을 받고 있다. ${ }^{8}$

IPMC의 유용한 특성으로 인해 이미 많은 연구자들 이 다양한 응용방안을 제시하였다. Kamamichi et. al 은 IPMC 액추에이터와 센서를 뱀의 형태를 가진 수영 로봇으로 제안하였다. ${ }^{9)}$ Mojarred et. al은 IPMC를 생 물모방 해저 로봇의 추진시스템에서 이용되는 프로펠러 로 사용하였다. ${ }^{10)}$ 2007년에는 Guo et. al은 해파리와 같은 해저 로봇을 만드는데 IPMC 액추에이터를 사용하 였다. ${ }^{11)}$ Krishen et. al은 우주 임무에서의 IPMC 어플 리케이션을 제안하였다. ${ }^{12)}$ 2015년 Shen et. al은 IPMC 센서를 사용하여 해저 차량을 제작하였다. ${ }^{13)}$ Palmre et. al은 생물에서 영감을 받은 IPMC 액추에이터로 구 부리고 휘는 것이 가능한 지느러미를 만들었다. ${ }^{7)}$ 소프 트 로보틱스에서 소프트 액추에이터로써의 쓰임새 말고 도 IPMC는 광학시스템에 활용될 수 있는데, 컴팩트 카 메라의 자동 초점 시스템이나 내시경에서 사용되는 기

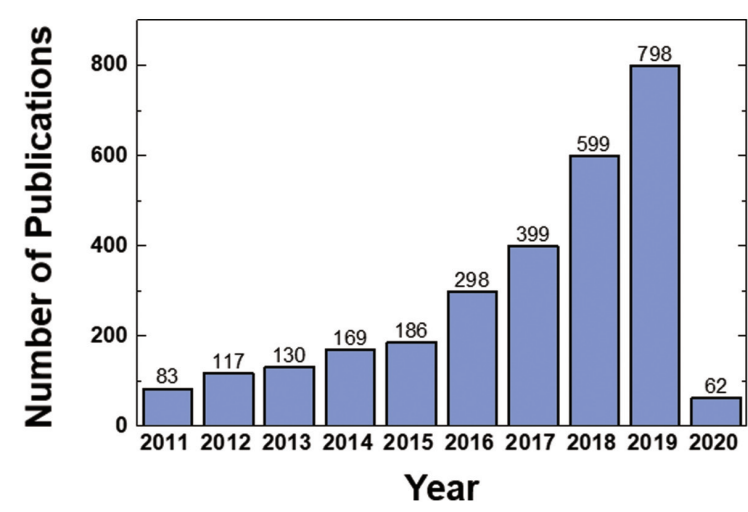

Fig. 1. 최근 10년간 발간된 소프트 액추에이터 관련 논문 추이

울임 액추에이터와 같은 곳에 사용된다. ${ }^{14,15)}$ 이와 더불 어 Tripathi et. al은 IPMC 액추에이터를 능동형 카테 터 가이드 와이어 시스템에 사용할 수 있도록 개발하는 데 성공하였다. ${ }^{16)}$ 2018년에는 IPMC를 사용한 재활용가 능 점자 디스플레이 어플리케이션을 선보였다. ${ }^{17)}$ 최근에 Chang et. al은 약을 전달 기구로 사용하면서 생물의 학 분야로도 활용도를 넓혀 가고 있다. ${ }^{18)}$ 그러나 IPMC 도 물질의 특성으로 인해서 넘어야할 문제들이 존재한 다. 예를 들어, $\mathrm{DC}$ 전압에서의 스트레인 약화, 낮은 출 력, 용매 증발, 표준화되지 않은 준비 과정 등의 요소들 이 IPMC의 센서나 액추에이터로써의 사용을 제한하고 있지만 개선될 여지가 많다. ${ }^{6}$ 최근 몇 년 간 기존 문제 점들을 해결하고 더 나아가 소프트 로보틱스 분야에 활 용하기 위한 다양한 방안들이 제시되었다. 그 중 하나는 준비단계의 최적화와 개선을 통해 표면전극을 균등하게 형성하는 것이다. ${ }^{19}{ }^{20)}$ 균등한 표면전극은 샘플이 균일한 성능을 낼 수 있게 해준다. Relaxation 문제를 해결하고 자 하는 노력으로는 물을 기반으로 한 IPMC의 경우 물 의 함량을 조절하거나 아예 물을 비휘발성 용매로(주로 이온성 액체) 대체 하는 것이 있다. ${ }^{21-24)}$

이 논문은 위에 서술한 $\mathrm{IPMC}$ 가 가지고 있는 문제점들 의 해결법으로 제시된 표면 전극의 최적화, 고분자 분리 막, 전극 표면 등등을 알아보고자 한다. 이 논문은 다음 과 같은 세 개의 절로 구성되어 있다. 첫 번째로 IPMC 의 구동원리를 소개하고, $\mathrm{IPMC}$ 의 아웃풋을 최적화하기 


\section{특 집 ㅍ 호동해, 조수영, 최윤영, 최영진, 조정호}

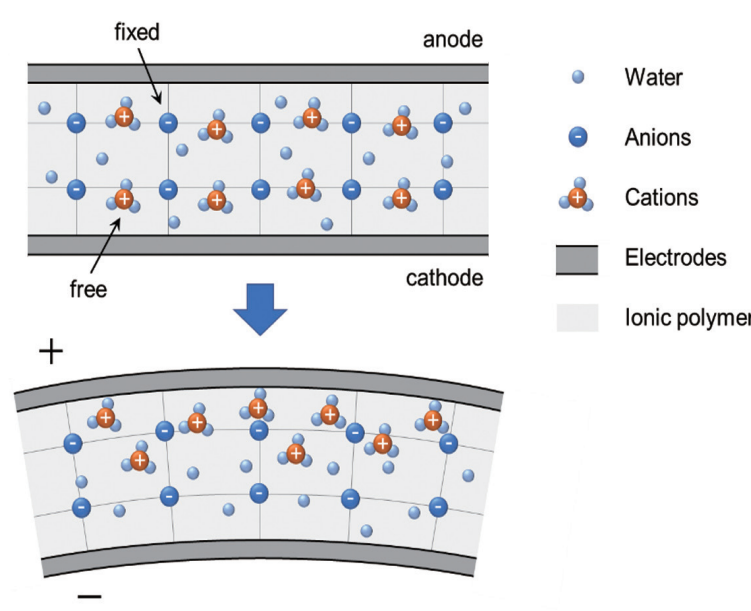

Fig. 2. IPMC 액추에이터 작동 원리

위한 다양한 방법인 샘플 준비단계 최적화, relaxation 제거, 출력 개선을 다루고, 마지막으로 IPMC를 센서로 써 응용하는 방법에 대해 간단히 논의하고자 한다.

\section{PMC 변형 및 센싱 메퀴니즘}

일반적으로 IPMC는 세 개의 층으로 구성되어 있다. 전해질 분리막과 두 개의 귀금속층이 분리막의 두 면 에 샌드위치 같이 존재하는 구조이다. 액추에이팅을 하 는 메커니즘은 그림 2에 제시하였다. Nafion, Flemion, Aciplex와 같은 물질들이 화학적 구조가 유사하기 때문 에 IPMC에서 기본 멤브레인으로 쓰인다. ${ }^{25)}$ 전극층은 기 본 멤브레인 층의 양면에 도금하여 형성하는데 금, 백 금, 팔라듐과 같은 귀금속 염이나 혼합된 염들을 사용 한다. ${ }^{23} \mathrm{IPMC}$ 에 전기장이 가해지게 되면 분리막 내부 에 있던 양이온과 물분자가 같이 음극으로 이동하게 된 다. 결과적으로 양이온과 물분자의 농도가 이방성으로 분포하게 되고 IPMC의 음극 부근에서 변형이 일어나게 되며 양극으로 $\mathrm{IPMC}$ 가 구부러지는 현상이 나타나게 된 다. ${ }^{26)}$ 마찬가지로 기계적인 변형이나 다른 자극이 가해 지게 되면 IPMC 내부에서 발생하는 변형율의 그라데이 션으로 인한 이온의 이동이 일어나고 결과적으로 IPMC 의 양 전극에서 전위차를 형성하게 된다. ${ }^{8)}$ 위에 서술한 내용을 통해 우리는 IPMC가 분리막이 존재하는 중간
층, 양이온, 용매, 그리고 전극층까지 총 4가지로 구성 되어 있는 것을 알 수 있다. 많은 연구자들이 이러한 작 동 원리를 이해하고 4가지 구성 요소들을 향상시키기 위 해서 연구를 진행해왔다.

\section{3. $\mathrm{PMC}$ 액추에이션 성능 쵝적화를 위한 방법}

현재 최첨단 IPMC 제조기술들은 일반적으로 네 가지 단계를 반드시 포함한다. 표면 사전처리, 초기 합성과정 (함침 환원, 환원제 보급), 표면 전극 형성(물리적 증착, 전기도금), 이온 교환 단계로 이루어져 있다. 각각의 단 계는 IPMC의 성능에 영향을 주는 다양한 요인들을 가지 고 있는데 이 중에서 핵심요인들을 최적화하는 것이 필 요하다. 2012년 Chang et. al은 팔라듐을 전극으로 사 용하는 IPMC의 효과적인 준비 방법을 제안하였다. ${ }^{27)}$ 논 문에 따르면 전체적인 준비과정을 세 가지 핵심적인 단 계로 나눌 수 있는데 첫 번째는 전처리, 두번째는 함침 환원 도금, 마지막으로 자가촉매적 도금이다.

$\mathrm{IPMC}$ 의 자체적인 물성도 성능에 영향을 주는데 표면 저항, 구부림 저항, 유전계수 같은 요소들이 대표적이 다. 2014년 Wang et. al은 IPMC의 물리적 성질과 전기 기계적 성질이 처리 단계에 의해서 어떻게 영향을 받는 지 보고하였다. ${ }^{28)}$ Wang et. al은 사전 처리, 함침 환원, 화학 도금과 같은 핵심적인 단계를 조합하여 서로 다른 특징을 가진 $\mathrm{IPMC}$ 를 제작하였다. 이를 통해 IPMC 성 능의 물리적 요인에 의한 영향과 표면과 인터페이스 전 극의 형성 메커니즘을 밝혀냈다. 사전처리는 거친 표면 을 형성하여 전극이 더 깊게 표면을 파고들 수 있게 만 들었고 구부림 저항을 감소시켰다. 함침 환원 과정은 중 간층인 분리막으로 전극이 더 세세하게 침투하는 것을 돕는 역할을 하였다. 또한 함침 환원으로 형성된 나노입 자 전극은 넓은 분산 영역은 $\mathrm{IPMC}$ 의 정전용량을 높이는 역할을 했다. 이러한 처리를 통해 준비된 샘플은 기존의 거칠지 않은 표면을 가진 IPMC와 비교하였을 때 $1.7 \mathrm{~V}$ 에서 최대 $10 \mathrm{~mm}$ 의 변형율을 보여 더 좋은 성능을 입증 하였다.

2016년에는 Stoimenov et. al은 모래분사 방법을 통 
해서 표면을 거칠게 하는 것이 계면전극 및 표면의 상태 에 어떤 영향을 끼치는지에 대한 연구를 발표하였다. ${ }^{29}$ 모래분사는 중간에 있는 분리막의 화학적인 손상없이 손쉽게 표면 거칠기를 통제하는 방법인데 모래분사 시 간과 모래입자의 사이즈를 조절하는 것으로 Nafion 표 면 프로파일을 다양하게 얻을 수 있음을 보여줬다. 이를 통해 얻어진 분리막을 이용하여 IPMC의 표면 저항, 등 가 모듈러스, 정전용량을 최적화에 성공하였다. ${ }^{30)}$

물을 용매로 쓰는 IPMC에 DC 전압이 인가되는 경 우 IPMC가 급속도로 변형되지만 초기의 지점으로 느리 게 돌아온다. ${ }^{31}{ }^{32)}$ 이 때 $\mathrm{IPMC}$ 가 초기 지점을 벗어나 회 복된다는 단점이 존재하는데 이것을 Relaxation effect 라고 한다. 이런 relaxation은 $\mathrm{IPMC}$ 가 갖는 가장 큰 단 점이며 액추에이터를 불안정하게 만들기 때문에 소프트 로보틱스로 사용을 제한하는 요소가 된다. 현재는 이러 한 단점을 극복하기 위한 두 가지 방식이 개발되었는데 첫 번째는 IPMC 물의 함량을 조절하는 방식이고 ${ }^{21,22)}$ 두 번째는 이온성 액체를 용매로 쓰는 방식이다. ${ }^{23,24)}$

IPMC에서 물의 함량은 relaxation에 영향을 주는 핵 심요소로 ${ }^{33)} \mathrm{Wang}$ et. al은 금 타입과 팔라듐 타입의 $\mathrm{IPMC}$ 들의 전기기계적 성질이 탈수에 의해서 어떤 영 향을 받는지에 대해 보고한 바가 있다. ${ }^{23)}$ 논문에 따르면 IPMC의 수분함량에 따라서 표면전극의 형태가 바뀌고, 더 나아가 액추에이션에서 중요한 역할을 하는 물리적 특성인 표면 저항, 정전용량, 단단함 등에도 영향을 준 다는 것을 보여줬다.

전통적으로 Nafion 117은 IPMC에 가장 많이 이용되 는 분리막으로 $180 \mathrm{um}$ 정도의 두께를 가지고 있다. 그런 데 Nafion 117을 사용한 IPMC의 경우에는 얇은 두께로 인해 $10 \mathrm{mN}$ 보다 낮은 출력을 보여서 높은 출력을 요구 하는 곳에서는 쓰는 것이 제한되었다. 이런 문제를 해결 하기 위한 가장 효과적인 방법은 더 두꺼운 분리막을 사 용하는 것이다. 두꺼운 분리막을 제작하기 위해 용액 캐 스팅방식이 제안되었다. ${ }^{21}{ }^{34)}$ 이를 통해 만들어진 IPMC 는 두께 $1.12 \mathrm{~mm}$, 너비 $4 \mathrm{~mm}$, 길이 $30 \mathrm{~mm}$ 의 제원을 갖 고 $3 \mathrm{~V}$ 의 전압에서 $44.1 \mathrm{mN}$ 의 출력을 보였다. 2011 년에 는 He et. al은 다양한 두께의 IPMC 성능을 보고하였는
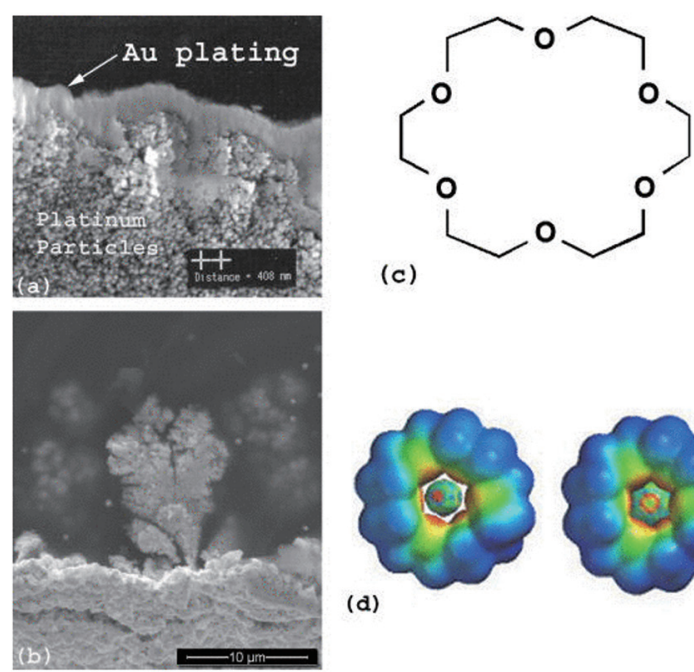

(c)
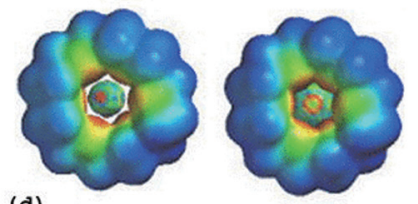

(d)

Fig. 3. (a) 금과 백금으로 전기 도금된 Nafion-117의 단면 SEM 사 진. (b) 금으로 전기 도금된 Flemion의 단면 SEM 사진 (c) 18-Crown-6의 화학구조 (d) 18-Crown-6에 둘러싸인 나 트륨 양이온(좌측)과 칼륨 양이온(우측) Journal of Applied Physics의 개제 허가를 받음.

데 $3.5 \mathrm{~V}$ 의 전압에서 $0.22 \mathrm{~mm}$ 에서 $0.42 \mathrm{~mm}, 0.8 \mathrm{~mm}$ 로 증가함에 따라 변형은 각각 $26.1 \%, 46.3 \%$ 감소하였으 나 출력에서는 각각 $100.6 \%, 13.8 \%$ 의 성능 향상을 가져 왔다. ${ }^{35)}$ 이러한 결과를 토대로 Nafion 분리막의 두께가 증가함에 따라 IPMC의 출력이 향상됨을 알 수 있다.

다른 출력향상 방법으로는 IPMC의 고분자 분리막에 첨가물을 주입하는 방식이 있다. Guo et. al은 수용해성 설폰화 다층 탄소나노튜브를 Nafion에 주입하여 낮은 전압에서도 높은 변형을 보이는 새로운 종류의 IPMC를 개발하였고 $3 \mathrm{~V}$ 의 전압이 가해졌을 때 $9.2 \mathrm{mN}$ 의 출력을 보였다. ${ }^{36)}$ Wang et. al 경우에는 고분자 분리막을 용액 캐스팅을 할 때 첨가물을 넣어서 그에 따른 영향을 보는 연구를 보고하였다. ${ }^{37)}$ 에틸렌글리콜, 디메틸설폭사이드, $\mathrm{N}, \mathrm{N}$-디메틸포름아미드, N-메틸포름아미드를 주입하 였을 때의 영향을 보았는데, 에틸렌글리콜을 주입하여 제작한 IPMC 액추에이터는 $4 \mathrm{~mm}$ 라는 큰 변형과 $2 \mathrm{~V}$ 전 압에서 $1.5 \mathrm{mN}$ 의 출력으로 첨가물이 없는 IPMC 액추에 이터에 비해 높은 전기기계적 특성을 보였다. 추가적으 로 Dai et. al은 분리막과 양이온의 종류를 최적화하여 


\section{특 집 표 호동해, 조수영, 최윤영, 최영진, 조정호}

a

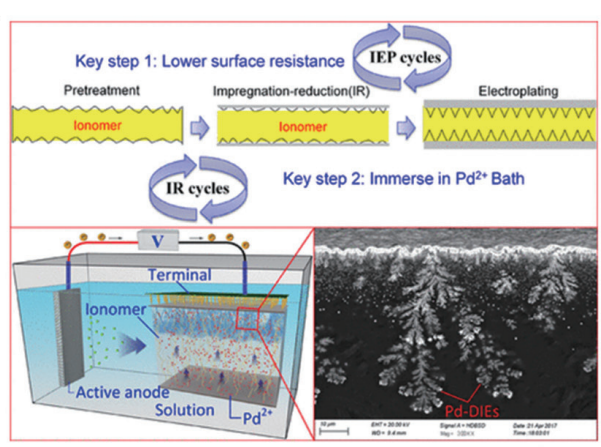

b

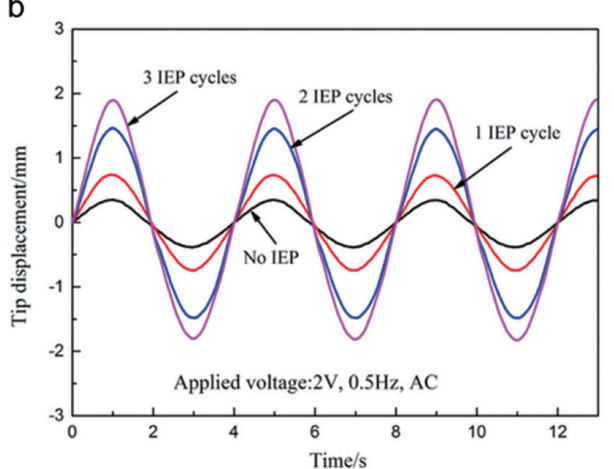

Fig. 4. (a) 전처리, 함침 환원, 전기 도금 과정을 거쳐 팔라듐 계면전극 형성하는 과정과 IPMC 표면내에서 생성된 dendritic 계면전극의 단 면 SEM 사진 (b) 함침 환원 횟수에 따른 IPMC액추에이터의 변형 그래프(2V, $0.5 \mathrm{~Hz}$ 의 교류 전압) ${ }^{45}$. ACS Applied Materials and Interfaces의 개제 허가를 받음.

출력을 높이고자 하였으며, IPMC에 다양한 첨가물을 주입하고자 하는 시도 또한 이루어졌다. ${ }^{38)}$ 이러한 방법 외에도 새로운 구조를 도입하여 출력을 높이고자 하는 시도가 있었다. 2018년 Chang et. al은 한쪽 면만 전극 이 있는 IPMC 액추에이터를 선보였는데 S자로 큰 변형 이 일어나면서도 높은 출력을 보였다. ${ }^{39)}$

$\mathrm{IPMC}$ 는 이오노머와 그 양쪽에 붙어있는 금속 전극으 로 구성된다. 이오노머와 표면 전극사이에는 계면층이 있는데 이 층이 IPMC의 성능에 많은 영향을 준다. 특히 $\mathrm{IPMC}$ 의 액추에이션 능력은 이 층에 의한 영향을 많이 받는 것이 명확하게 알려졌는데 이는 계면 면적의 증가 가 액추에이션에 직접적인 영향을 주는 정전용량의 증 가를 유도하기 때문이다. ${ }^{40)}$

현재까지 IPMC 계면 전극은 dendritic과 granular타 입으로 분류되었다. Asaka et. al은 금을 이용한 IPMC 의 dendritic 계면 전극을 개발하였고, ${ }^{41)}$ 이어서 Chen과 Kim et. al은 각각 백금과 팔라듐을 사용한 granular 타입의 계면전극을 개발하였다. ${ }^{42)}$ 이 전극들을 이용한 $\mathrm{IPMC}$ 의 정전용량은 각각 $1.5,0.22,0.34 \mathrm{mF} / \mathrm{cm}^{2}$ 로, 금을 이용하여 만든 dendritic 계면 전극이 다른 구조에 비해서 7 배에서 4 배가량 증가한 정전용량을 가지는 것 을 보였다. 이렇게 계면전극의 구조를 바꿈으로써 정전 용량을 늘리고 이로 인해 IPMC의 전기기계적 특성을 효 과적으로 증가시킬 수 있게 되었다.
위에 보고된 논문들을 통하여 알게 된 계면 전극의 중 요성으로 인해 최근에는 넓은 계면전극을 형성하는 것 에 초점을 맞추고 있는 연구가 등장하였고, 함침 환원, 환원제 삼투, 용액 캐스팅과 같이 화학적인 방법이나 직 접적으로 $\mathrm{IPMC}$ 를 제작하는 과정에서 계면 면적을 늘리 는 방법이 존재한다. 함침 도금 방법과 환원제 삼투 방 법을 조합하면 이오노머 안쪽에서 팔라듐, 백금, 은, 구 리 계면 전극의 면적을 증가시키는 dendritic 계면 전 극을 형성하는 것이 가능하다는 것이 보고되었다. ${ }^{43)}$ Dendritic 계면 전극 형성은 금속의 소비량을 줄이면서 도 계면 면적을 늘리는 것으로 밝혀져 ${ }^{44)} \mathrm{IPMC}$ 의 성능을 향상시키는데 좋은 방법으로 알려졌지만, 처음으로 이 를 보고한 연구에 따르면 dendritic 계면전극의 형성은 금 이온이 섞인 용액에 반복적으로 함침 환원을 하는 것 이 유일한 방법이었다.

Wang et. al은 팔라듐, 백금, 금, 구리 dendritic 계면전극을 빠르고 간단하면서도 효율적으로 고분 자 분리막 사이에 형성하는 방법을 제시했는데 팔라듐 dendritic 계면전극을 예시로 들면 다음과 같은 방식으 로 전극을 형성하게 된다. ${ }^{45}$ 첫 번째, Nafion 분리막의 표면을 거칠기를 높여서 표면적을 늘리는데 이는 팔라 듐 이온이 함유된 용액에서 함침 환원이 원활하게 일어 날 수 있도록 만들어준다. 이어서 팔라듐 이온을 기존 에 Nafion 분리막에 있던 이온들과 교환하는 과정을 거 


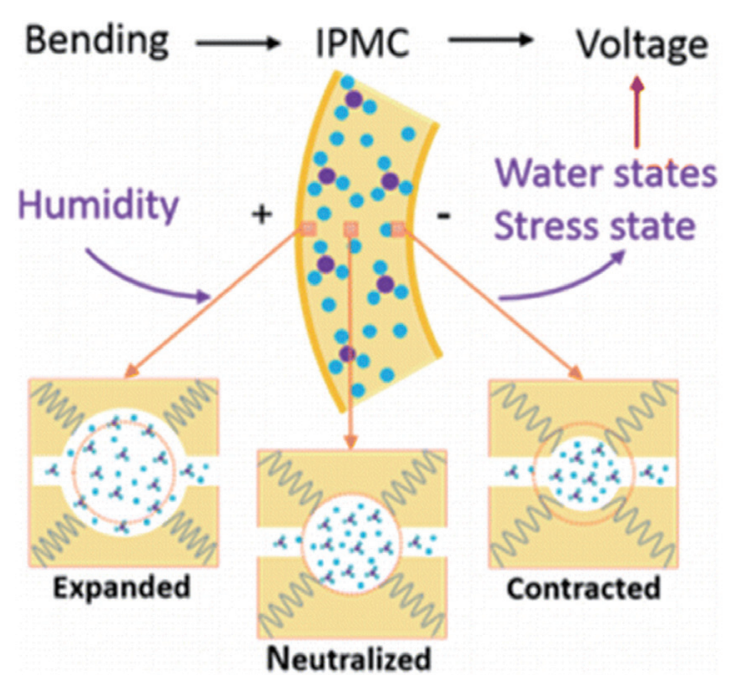

Fig. 5. 습도가 증가할 경우 발생하는 기계적 변화에 의한 전압 증 가 메커니즘 모식도 ${ }^{50}$ Journal of Physical Chemistry의 개 제 허가를 받음.

친 뒤 함침 환원을 진행한다. 함침 환원 과정은 표면에 서부터 일어나게 되고 팔라듐 원자들은 두께가 두꺼워 지는 방향으로 점점 더 성장하게 된다. 마지막으로 팔라 듐을 포함하고 있는 Nafion 분리막을 전기도금을 한다. 화학적 반응이 점차 진행됨에 따라 원래 분리막 안에 있 던 팔라듐 입자들에 다른 팔라듐이 붙고 성장하여 주 가 지로 자라게 되고 거기에 또다른 입자들이 붙어서 다른 가지들을 형성하게 된다. 이러한 방식으로 성장하게 된 dendritic 팔라듐 계면 전극은 중간층인 이온성 폴리머 를 뚫고 반대편과 닿을 때까지 성장하는 것도 가능하다. 이러한 dendritic 계면 전극들은 IPMC의 액추에이션 성 능 향상에 원동력이 되었으며 액추에이션 성능 향상은 소프트 로보틱스 분야에서의 액추에이터로써의 활용을 앞당길 것이다.

\section{IPMC 센서}

외부에서 주어진 자극에 의해서 IPMC 내부의 이온 이 동이 전기적인 반응으로 이어진다는 것은 잘 알려져 있 는 사실이다. ${ }^{46)}$ 이러한 메커니즘을 응용하여 IPMC는 소프트 로보틱스 분야의 다양한 센서로써 변형감지, 속
력, 습도뿐만 아니라 이온의 분포를 통한 IPMC 위에서 의 위치까지 감지하는 것이 가능하다. 최근에는 이러한 센서로써의 IPMC 성능을 최적화하기 위한 많은 연구들 이 진행되고 있다. Yamakita et. al은 IPMC를 이용하 여 액추에이션과 센싱을 동시에 할 수 있는 연구를 보고 하였고, ${ }^{9)}$ Shahinpoor et. al은 IPMC를 이용하여 $1 \mathrm{~mm}$ 이하의 변형에서 $2 \mathrm{mV}$ 의 출력을 가지는 켄틸레버 센서 를 개발하였다. ${ }^{47)}$ 뿐만 아니라 Konyo et. al은 IPMC 켄틸레버를 이용하여 속도를 감지하는 센서를 개발하 였고 $1 \sim 12 \mathrm{mV} /(\mathrm{m} / \mathrm{s})$ 의 감지능력을 보이는 것을 입증 하였다. ${ }^{48)}$

이러한 여러가지 응용안에도 불구하고 IPMC는 단점 을 가지고 있는데 그것은 바로 낮은 전기적 응답이다. 이러한 점을 해결하고자 Zhu et. al은 용액 공정을 이용 한 $3 \times 3$ 배열의 새로운 형태를 가진 IPMC 센서를 제안 하였다. ${ }^{49)}$ 대칭적인 구조인 두 개의 IPMC가 동시에 반 응하며 그로 인해 발생하는 전압차를 감지하는 센서인 데 출력 전압이 $25 \mathrm{mV}$ 까지 증가하는 것을 보였다.

더 나아가 Zhu et. al은 금을 이용한 IPMC 센서를 다 양한 습도환경에 노출시켜 습도에 의한 영향을 알아보 는 연구를 진행하였다. 연구에 따르면 IPMC 센서의 전 기적인 응답은 습도에 의해서 많은 영향을 받는 것으로 밝혀졌으며 이는 IPMC의 습도 센서로써 응용 가능성을 보여줬다. 구조적인 이점을 취하기 위한 노력은 다른 연 구팀에서도 계속해서 이뤄졌다. ${ }^{50)}$ Lei et. al은 기존의 스트립 형태의 IPMC가 아닌 튜브 형태의 IPMC를 선보 였는데, 튜브 축 방향을 제외한 다른 방향에서 오는 모 든 자극들에 대해서 물리적인 변화를 감지할 수 있는 특 성을 지녔다. ${ }^{51)}$ 최근에는 $\mathrm{Zhu}$ et. al이 새로운 구조의 $\mathrm{IPMC}$ 를 선보였는데 용액 공정을 통해서 제작된 피라미 드 형태의 센서는 기존의 스트립 형태의 IPMC에 비해 서 훨씬 높은 응답신호를 보였다. ${ }^{52)}$

Zhu et. al은 구조적 변화에서 벗어나 다양한 습도에 서 다양한 양이온을 사용할 때 발생하는 IPMC 센서의 전기적 응답 또한 보고하였다. ${ }^{50)}$ Volpini et. al은 IPMC 가 압축될 때 예상되는 이온의 움직임을 예측하는 모델 을 제안하였다. ${ }^{53)}$ 2017년에는 Gudarzi et. al은 스트리 
밍 전위가설을 기반으로 IPMC 동적 압력 센서를 설계 한 다음 이를 이용하여 압축 및 전단 모드의 외부 압력 으로 인해 작동하는 충전 전류 생성 메커니즘을 제시하 였다. ${ }^{54,}{ }^{55)}$ Wang et. al은 IPMC센서의 두께와 같은 제 원을 고려하여 $\mathrm{IPMC}$ 가 가지는 두께, 길이, 폭을 통해 센서의 성능을 예측하는 논문을 보고하였다. ${ }^{56)}$

\section{5. 결론}

지난 5년간 $\mathrm{IPMC}$ 를 사용한 소프트 로보틱스 어플리 케이션들이 재료과학, 물리화학, 화학, 고분자 과학, 전 기공학, 나노과학, 응용물리와 같은 다양한 분야에서 관 심을 불러일으켰다.

$\mathrm{IPMC}$ 는 유연한 특성을 갖고 전기적 신호를 물리적인 변형으로 변환할 수 있으며 경량성, 부드러움, 저전력 구동, 자가 감지능력 등 소프트 로보틱스 분야에서 활 용될 수 있는 무궁무진한 잠재력을 가지고 있다. 하지만 이러한 잠재성과 함께 낮은 출력, relaxation과 같은 문 제점을 동시에 가지고 있기에 여전히 소프트 로보틱스 에 사용될 수 있는 부분은 제한되고 있다.

이러한 문제점을 해결하기 위해서 IPMC 준비 단계에 서 전처리가 연구되고 있다. 최근에는 사포처리, 화학 부식, 플라즈마 식각, 샌드 블래스팅 등과 같은 방법이 부각되고 있다. 사포를 이용하여 표면 거칠기를 증가시 키는 방식은 인적 요소가 개입되어 불균일한 표면이 형 성될 수 있다. 화학부식이나 플라즈마 식각의 경우에는 균일한 표면을 얻을 수 있지만 분리막 표면의 분자구조 가 쉽게 변질될 수 있다는 단점이 있다. 샌드 블래스팅 을 이용한 방법 또한 균일한 표면을 얻는 것은 힘들다는 단점이 있다. 그러므로 균일하면서도 거친 Nafion 표면 을 얻기 위한 새로운 방법이 필요하다.

Relaxation을 제거하기 위한 기존의 방법들도 여전 히 단점을 가지고 있다. 이온성 액체로 용매를 대체하는 방법이 relaxation 문제를 해결할 수 있기는 하지만 반 대 급부로 반응 시간이 느려진다. 다른 방법인 분리막의 수분함량을 조절하는 방식이 이 문제를 해결하기 위한 좋은 방법이지만 미량의 수분함량 차이가 너무 큰 차이
를 불러일으키기 때문에 최적의 방법이라고 볼 수는 없 을 것이다. 또한 수분함량을 일정하게 유지하기 위해서 $\mathrm{IPMC}$ 자체를 봉지하는 과정이 필요하기 때문에 역시 다 양한 어려움이 존재한다. 그리고 relaxation 문제를 해 결하기 위해서 수분함량을 줄이는 것은 이온성 액체로 대체하는 것과 마찬가지로 반응 속도의 감소를 가져온 다. 따라서 relaxation을 감소시키는 것과 동시에 성능 을 극대화하는 것이 반드시 필요하다.

$\mathrm{IPMC}$ 의 성능을 끌어올리기 위한 가장 간단한 방법은 아무래도 IPMC의 두께를 늘리는 방식이다. 두께를 늘 리는 방식은 크게 두 가지로 나뉘는데, 첫 번째는 여러 개의 분리막을 가열 압착을 통해 하나의 분리막으로 만 드는 방식이 있고, 두 번째는 용액 공정을 통해 제작하 는 것이다. 두 방식 모두 단점을 가지고 있는데 가열 압 착 공정의 경우 장기간 사용할 경우 단일 분리막 계면에 서 탈락이 일어날 가능성이 크다는 것이고, 용액 공정의 경우에는 변형이 감소하고 응답시간이 줄어든다는 것이 다. Zhu et. al은 IPMC의 응답 속도를 증가시키기 위해 서 고전압 펄스를 가하는 방식을 제안하였는데 초기에 변형이 잘 일어나지 않는 점을 고려하여 두꺼운 IPMC 에서 변형이 일어나지 않는 점을 해결하였다. ${ }^{57)}$

결론적으로 위 해결방안들을 통해 $\mathrm{IPMC}$ 가 가지고 있 는 모든 문제점들을 완벽하게 해결할 수는 없다. 하지만 $\mathrm{IPMC}$ 가 가지고 있는 여러 장점들을 유지하며 단점을 보완할 수 있는 연구들이 꾸준히 진행된다면, 소프트 로 보틱스 분야에 사용되는 액추에이터와 센서로써의 사용 이 머지않은 미래에 가능할 것이다.

\section{REFERENCES}

1. A. T. Abdulsadda; X. Tan "An Artificial Lateral Line System Using Ipmc Sensor Arrays”. Int. J. Smart Nano Mater., 3 [3] 226-242 (2012).

2. C. K. Chung; P. K. Fung; Y. Z. Hong; M. S. Ju; C. C. K. Lin; T. C. Wu "A Novel Fabrication of Ionic Polymer-Metal Composites (Ipmc) Actuator with Silver Nano-Powders". Sensor. Actuat. B-Chem., 117 [2] 367-375 (2006).

3. S. Guo; Y. Ge; L. Li; S. Liu In Underwater 
Swimming Micro Robot Using Ipmc Actuator, 2006 International Conference on Mechatronics and Automation, IEEE: 2006; pp 249-254.

4. K. Jung; J. Nam; H. Choi "Investigations on Actuation Characteristics of Ipmc Artificial Muscle Actuator”. Sensor. Actuat. A-Phys., 107 [2] 183-192 (2003).

5. K. Surana; P. K. Singh; B. Bhattacharya; C. S. Verma; R. M. Mehra "Synthesis of Graphene Oxide Coated Nafion Membrane for Actuator Application”. Ceram. Int., 41 [3] 5093-5099 (2015).

6. B. Bhandari; G.-Y. Lee; S. -H. Ahn "A Review on Ipmc Material as Actuators and Sensors: Fabrications, Characteristics and Applications". Int. J. Pr. Eng. Man., 13 [1] 141-163 (2012).

7. V. Palmre; J. J. Hubbard; M. Fleming; D. Pugal; S. Kim; K. J. Kim; K. K. Leang "An Ipmc-Enabled Bio-Inspired Bending/Twisting Fin for Underwater Applications". Smart Mater. Struct., 22 [1] 014003 (2012).

8. R. Tiwari; K. J. Kim "Ipmc as a Mechanoelectric Energy Harvester: Tailored Properties”. Smart Mater. Struct., 22 [1] 015017 (2012).

9. N. Kamamichi; M. Yamakita; K. Asaka; Z.-W. Luo In A Snake-Like Swimming Robot Using Ipmc Actuator/Sensor, Proceedings 2006 IEEE International Conference on Robotics and Automation, 2006. ICRA 2006., IEEE: 2006; pp 1812-1817.

10. M. Mojarrad; M. Shahinpoor In Biomimetic Robotic Propulsion Using Polymeric Artificial Muscles, Proceedings of International Conference on Robotics and Automation, IEEE: 1997; pp 2152-2157.

11. S. Guo; L. Shi; X. Ye; L. Li In $A N e w$ Jellyfish Type of Underwater Microrobot, 2007 International Conference on Mechatronics and Automation, IEEE: 2007; pp 509-514.

12. K. Krishen "Space Applications for Ionic Polymer-Metal Composite Sensors, Actuators, and Artificial Muscles”. Acta Astronaut., 64 [11-12] 1160-1166 (2009).

13. Q. Shen; T. M. Wang; K. J. Kim "A Biomimetic Underwater Vehicle Actuated by Waves with Ionic Polymer-Metal Composite Soft Sensors".
Bioinspir. Biomim., 10 [5] 055007 (2015).

14. H. K. Lee; N. J. Choi; S. Jung; K. H. Park; H. Jung; J. K. Shim; J. W. Ryu; J. Kim "Electroactive Polymer Actuator for LensDrive Unit in Auto-Focus Compact Camera Module". ETRI J., 31 [6] 695-702 (2009).

15. S.-i. Son; D. Pugal; T. Hwang; H. R. Choi; J. C. Koo; Y. Lee; K. Kim; J.-D. Nam "Electromechanically Driven VariableFocus Lens Based on Transparent Dielectric Elastomer". Appl. Opt., 51 [15] 2987-2996 (2012).

16. A. Tripathi; B. Chattopadhyay; S. Das "Cost-Effective Fabrication of Ionic Polymer Based Artificial Muscles for CatheterGuidewire Maneuvering Application”. Microsyst. Technol., 25 [3] 1129-1136 (2019).

17. Y. Bar-Cohen "Electroactive Polymers for Refreshable Braille Displays". SPIE Newsroom, 11 (2009).

18. X. L. Chang; P. S. Chee; E. H. Lim; W. C. Chong "Radio-Frequency Enabled Ionic Polymer Metal Composite (Ipmc) Actuator for Drug Release Application”. Smart Mater. Struct., 28 [1] 015024 (2018).

19. S. J. Kim; I. T. Lee; Y. H. Kim "Performance Enhancement of Ipmc Actuator by Plasma Surface Treatment". Smart Mater. Struct., 16 [1] N6 (2007).

20. M. Shahinpoor; K. J. Kim "The Effect of Surface-Electrode Resistance on the Performance of Ionic Polymer-Metal Composite (Ipmc) Artificial Muscles”. Smart Mater. Struct., 9 [4] 543 (2000).

21. S. -G. Lee; H.-C. Park; S. D. Pandita; Y. Yoo "Performance Improvement of Ipmc (Ionic Polymer Metal Composites) for a Flapping Actuator". Int. J. Control Autom., 4 [6] 748755 (2006).

22. K. Kikuchi; S. Tsuchitani "Nafion $\AA$-Based Polymer Actuators with Ionic Liquids as Solvent Incorporated at Room Temperature”. J. Appl. Phys, , 106 [5] 053519 (2009).

23. Y. Wang; H. Chen; Y. Wang; Z. Zhu; D. Li "Effect of Dehydration on the Mechanical and Physicochemical Properties of Gold- 
and Palladium-Ionomeric Polymer-Metal Composite (Ipmc) Actuators”. Electrochim. Acta, 129 450-458 (2014).

24. Z. Zhu; K. Asaka; L. Chang; K. Takagi; H. Chen "Physical Interpretation of Deformation Evolvement with Water Content of Ionic Polymer-Metal Composite Actuator". J. Appl. Phys., 114 [18] 184902 (2013).

25. U. Deole; R. Lumia; M. Shahinpoor; M. Bermudez "Design and Test of Ipmc Artificial Muscle Microgripper". J. Micro. Nano, Mechatron., 4 [3] 95-102 (2008).

26. K. Jung; J. Nam; H. Choi "Investigations on Actuation Characteristics of Ipmc Artificial Muscle Actuator". Sensor. Actuat. A-Phys., 107 [2] 183-192 (2003).

27. L. Chang; H. Chen; Z. Zhu; B. Li "Manufacturing Process and Electrode Properties of PalladiumElectroded Ionic Polymer - Metal Composite". Smart Mater. Struct., 21 [6] 065018 (2012).

28. Y. Wang; Z. Zhu; H. Chen; B. Luo; L. Chang; Y. Wang; D. Li "Effects of Preparation Steps on the Physical Parameters and Electromechanical Properties of Ipmc Actuators". Smart Mater. Struct., 23 [12] 125015 (2014).

29. B. L. Stoimenov; J. M. Rossiter; T. Mukai In Anisotropic Surface Roughness Enhances the Bending Response of Ionic Polymer-Metal Composite (Ipmc) Artificial Muscles, Smart Materials IV, International Society for Optics and Photonics: 2006; p 641302.

30. Y. Wang; Z. Zhu; J. Liu; L. Chang; H. Chen "Effects of Surface Roughening of Nafion 117 on the Mechanical and Physicochemical Properties of Ionic Polymer-Metal Composite (Ipmc) Actuators". Smart Mater. Struct., 25 [8] 085012 (2016).

31. X. Bao; Y. Bar-Cohen; S.-S. Lih In Measurements and Macro Models of Ionomeric PolymerMetal Composites (Ipmc), Smart Structures and Materials 2002: Electroactive Polymer Actuators and Devices (EAPAD), International Society for Optics and Photonics: 2002; pp 220-227.

32. M. Annabestani; M. Maymandi-Nejad; N.
Naghavi "Restraining Ipmc Back Relaxation in Large Bending Displacements: Applying Non-Feedback Local Gaussian Disturbance by Patterned Electrodes". IEEE T. Electron. Dev., 63 [4] 1689-1695 (2016).

33. D. K. Biswal; D. Bandopadhya; S. K. Dwivedy "Dynamic Modeling and Effect of Dehydration on Segmented Ipmc Actuators Following Variable Parameter Pseudo-Rigid Body Modeling Technique". Mech. Adv. Mater. Struc., 21 [2] 129-138 (2014).

34. J. H. Park; S. W. Lee; D. S. Song; J. Y. Jho "Highly Enhanced Force Generation of Ionic Polymer-Metal Composite Actuators Via Thickness Manipulation". ACS appl. mater. interfaces, 7 [30] 16659-16667 (2015).

35. Q. S. He; M. Yu; L. L. Song; H. T. Ding; X. Q. Zhang; Z. D. Dai "Experimental Study and Model Analysis of the Performance of Ipmc Membranes with Various Thickness". $J$ Bionic Eng, 8 [1] 77-85 (2011).

36. D. Guo; H. Ding; H. Wei; Q. He; M. Yu; Z. Dai "Hybrids Perfluorosulfonic Acid Ionomer and Silicon Oxide Membrane for Application in Ion-Exchange Polymer-Metal Composite Actuators". Sci. China Series, E: Techno. Sci., 52 [10] 3061-3070 (2009).

37. Y. Wang; H. Chen; Y. Wang; B. Luo; L. Chang; Z. Zhu; B. Li "Influence of Additives on the Properties of Casting Nafion Membranes and So-Based Ionic Polymer - Metal Composite Actuators”. Polym. Eng. Sci., 54 [4] 818-830 (2014).

38. C.-A. Dai; C.-J. Chang; A.-C. Kao; W.-B. Tsai; W.-S. Chen; W.-M. Liu; W.-P. Shih; C. -C. Ma "Polymer Actuator Based on Pva/ Pamps Ionic Membrane: Optimization of Ionic Transport Properties". Sensor. Actuat. A-Phys. , 155 [1] 152-162 (2009).

39. L. F. Chang; L. F. Yu; C. Q. Li; Q. Z. Niu; Y. Hu; P. Lu; Z. C. Zhu; Y. C. Wu "Ionic Polymer with Single-Layered Electrodes: A Novel Strategy for Ionic Actuator Design”. Smart Mater. Struct., 27 [10] (2018).

40. M. Safari; L. Naji; R. T. Baker; F. A. Taromi "The Enhancement Effect of Lithium Ions on 
Actuation Performance of Ionic Liquid-Based Ipmc Soft Actuators”. Polymer, 76 140-149 (2015).

41. N. Fujiwara; K. Asaka; Y. Nishimura; K. Oguro; E. Torikai "Preparation of Gold-Solid Polymer Electrolyte Composites as Electric Stimuli-Responsive Materials”. Chem. Mater., 12 [6] 1750-1754 (2000).

42. M. Shahinpoor; K. J. Kim "Novel Ionic Polymer-Metal Composites Equipped with Physically Loaded Particulate Electrodes as Biomimetic Sensors, Actuators and Artificial Muscles”. Sensor. Actuat. A-Phys., 96 [2] 125-132 (2002).

43. T. -G. Noh; Y. Tak; J.-D. Nam; H. Choi "Electrochemical Characterization of Polymer Actuator with Large Interfacial Area”. Electrochim. Acta, 47 [13] 2341-2346 (2002).

44. N. M. Shinde; J. M. Yun; R. S. Mane; S. Mathur; K. H. Kim "An Overview of SelfGrown Nanostructured Electrode Materials in Electrochemical Supercapacitors". J. Korean Ceram. Soc., 55 [5] 407-418 (2018).

45. Y. Wang; J. Liu; Y. Zhu; D. Zhu; H. Chen “ Formation and Characterization of Dendritic Interfacial Electrodes inside an Ionomer". ACS appl. mater. interfaces, 9 [36] 30258-30262 (2017).

46. Y. Bahramzadeh; M. Shahinpoor "Dynamic Curvature Sensing Employing Ionic-PolymerMetal Composite Sensors". Smart Mater. Struct., 20 [9] 094011 (2011).

47. M. Shahinpoor; Y. Bar-Cohen; T. Xue; J. Harrison; J. Smith Some Experimental Results on Ionic Polymer-Metal Composites (Ipmc) as Biomimetic Sensors and Actuators. SPIE: 1998; Vol. 3324

48. M. Konyo; Y. Konishi; S. Tadokoro; T. Kishima Development of Velocity Sensor Using Ionic Polymer-Metal Composites. SPIE: 2004; Vol. 5385
49. Z. Zhu; Y. Wang; X. Hu; X. Sun; L. Chang; P. Lu "An Easily Fabricated High Performance Ionic Polymer Based Sensor Network”. Appl. Phys. Lett., 109 [7] 073504 (2016).

50. Z. Zhu; T. Horiuchi; K. Kruusamäe; L. Chang; $\mathrm{K}$. Asaka "Influence of Ambient Humidity on the Voltage Response of Ionic Polymer - Metal Composite Sensor". J. Phys. Chem. B, 120 [12] 3215-3225 (2016).

51. H. Lei; M. A. Sharif; X. Tan "Dynamics of Omnidirectional Ipmc Sensor: Experimental Characterization and Physical Modeling". IEEE/ASME T. Mech., 21 [2] 601-612 (2016).

52. Z. Zhu; C. Bian; J. Ru; W. Bai; H. Chen "Rapid Deformation of Ipmc under a High Electrical Pulse Stimulus Inspired by Action Potential”. Smart Mater. Struct., 28 [1] 01LT01 (2018).

53. V. Volpini; L. Bardella; A. Rodella; Y. Cha; M. Porfiri "Modelling Compression Sensing in Ionic Polymer Metal Composites". Smart Mater. Struct., 26 [3] 035030 (2017).

54. M. Gudarzi; P. Smolinski; Q. M. Wang "Bending Mode Ionic Polymer-Metal Composite (Ipmc) Pressure Sensors”. Measurement, 103 250-257 (2017).

55. M. Gudarzi; P. Smolinski; Q. M. Wang "Compression and Shear Mode Ionic PolymerMetal Composite (Ipmc) Pressure Sensors". Sensor. Actuat. A-Phys., 260 [15] 99-111 (2017).

56. J. L. Wang; Y. J. Wang; Z. C. Zhu; J. H. Wang; Q. S. He; M. Z. Luo "The Effects of Dimensions on the Deformation Sensing Performance of Ionic Polymer-Metal Composites". Sensors-Basel, 19 [9] 2104 (2019).

57. Z. C. Zhu; C. S. Bian; J. Ru; W. F. Bai; H. L. Chen "Rapid Deformation of Ipmc under a High Electrical Pulse Stimulus Inspired by Action Potential". Smart Mater. Struct., 28 [1] 01LT01 (2019). 


\section{특 집 ㅍ 호동해, 조수영, 최윤영, 최영진, 조정호}

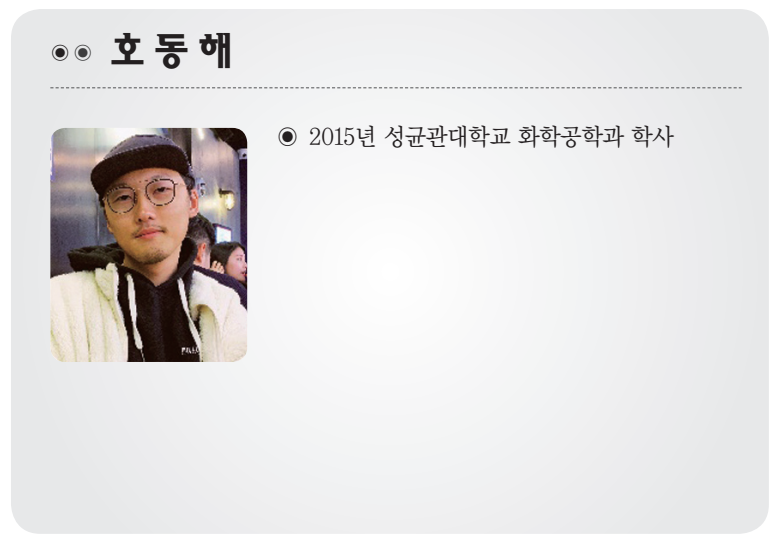

\section{ㄷㅊ최윤 영}

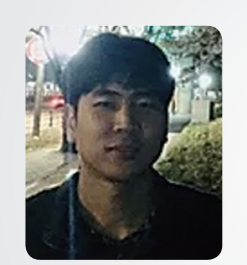

(- 2018년 성균관대학교 신소재공학과 학사

( 2020년 성균관대학교 나노과학기술학과 석사

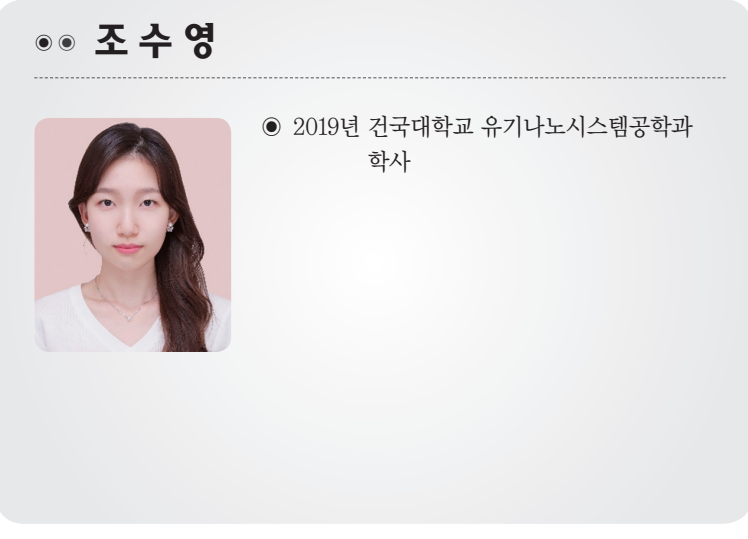

○○ 최영 진

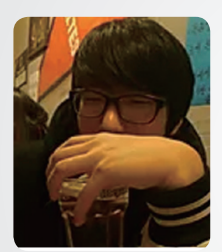

- 2015 년 성균관대학교 화학공학과 학사

\section{○• 조 정호}



- 2001년 서강대학교 화학공학과 학사

( 2006년 POSTECH 화학공학과 석사, 박사

- 2008년 숭실대학교 유기신소재 파이버공학과 조교수

( 2012년 성균관대학교 나노공학과 부교수, 교수

( 2019년 연세대학교 화공생명공학과 교수 